\title{
Evaluation of Silicon Concentration in Milk from Different Species and in Certain Dairy Products in Egypt
}

Mounira M. Ahmed'; Magda Abd

M. A. El Nawawy ${ }^{2}$

${ }^{1}$ Animal Production Res. Institute, Agric. Res. Center, Ministry of Agric.

${ }^{2}$ Food science Dept., Fac. of Agric., Ain Shams University.

${ }^{3}$ Institute of Africa Research and Studies - Cairo University

\begin{abstract}
Silicon plays an important role in bone formation and connective tissue metabolism. Although biological interest in this element has recently been increased, limited information exists about the silicon concentration of foods. Further knowledge relating the relationship between dietary silicon and human health, reliable silicon concentration in food is required. Therefore, the object of this study focused on the silicon concentration in some Egyptian milk and some dairy products. Milk from different species and some dairy products commonly consumed in Egypt were analyzed for silicon concentration. The samples were analyzed using Agilent microwave plasma atomic emission spectrometry following microwave- assisted digestion with nitric acid. The results revealed the linearity of this method and the recovery ranged from $98-100 \%$ for milk and $96-98$ for cheese. The data showed the highest concentration of silicon was found in camel milk (mean $=3.34 \pm 0.12 \mathrm{ppm}$ ), lowest concentration in buffalo milk (mean $=0.20 \pm 0.01 \mathrm{ppm}$ ). Also, it was found the mean values of silicon in goat and cow milk were $=2.28 \pm 0.09$ ppm and $0.94 \pm 0.03 \mathrm{ppm}$, respectively. The mean values of fresh skim milk and skim milk powder were $0.80 \pm 0.04$ and $33.11 \pm$ 2.3 , respectively. The silicon concentration in processed cheese was higher than that in soft cheese. However, yogurt was of the highest silicon concentration, compared to fresh milk and cheeses. The present study provided the importance of the primary data obtained dealing with the silicon concentration of some Egyptian milks and dairy products.
\end{abstract}

Keywords: silicon, skim, buffalo, cow, camel, goat milk, soft cheese, processed cheese, yoghurt, microwave plasma atomic emission spectrometry

\section{INTRODUCTION}

Silicon $(\mathrm{Si})$ is the third most abundant trace element of the human body and is of a potential beneficial influence, especially, in regard to connective tissues bone, skin, hair, nails and blood vessels. It also of vital effect on the protection from atherosclerotic vascular alterations and lowers plasma lipids (Sripanyakorn et al.2005) Limited knowledge is available on its required dietary intakes, and optimal levels needed for the prevention of bone and cardiovascular diseases. Different studies on the beneficial effect of silicon on bone health were reported. It usually exist in an abundant levels in foods derived from plants, and cereals, as silicon dioxide $\left(\mathrm{SiO}_{2}\right.$, silica $)$ and orthosilicic acid [Si $\left.(\mathrm{OH})_{4}\right]$. Lower levels, however, are detected in foods from animal sources Orthosilicic acid is the major silicon species presents in drinking and mineral water.. Insoluble phytolithic silicon silica are present in plants and plant-based foods but intestinal uptake proceeds following luminal hydrolysis to orthosilicic acid The silicon concentration in milk and dairy products appears to be low (Reffitt et al., 1999, EVM, 2003, Powell et al., 2005 and Jugdaohsingh, 2007)

Little information on the silicon concentration of foods has been reported, primarily due to difficulties associated with the analytical procedures required for silicon analysis and there are limited data available for milk and dairy products especially for Egyptian milks and its products.

Table 2. Chemical composition of tested dairy products

\begin{tabular}{lccccc} 
Parameters \% & Fresh Skim milk & Skim milk powder & White Soft cheese & Processed cheese & Yoghurt \\
\hline pH & 6.72 & 6.60 & 6.40 & 5.40 & 4.60 \\
T.S & 8.83 & 96.20 & 37.40 & 42.00 & 15.60 \\
Fat & 0.11 & 1.15 & 18.50 & 29.00 & 6.50 \\
Protein & 3.20 & 33.00 & 14.00 & 9.50 & 4.40 \\
Lactose & 4.70 & 54.00 & 1.50 & 2.50 & 3.60 \\
Ash & 0.82 & 8.05 & 1.00 & 1.10 \\
\hline
\end{tabular}

For the determination of silicon using Agilent microwave plasma atomic emission spectrometry.
Therefore, the aim of this study was to determine silicon level in milk from different animal species and some dairy products,

\section{MATERIALS AND METHODS}

Whole raw buffalo milk was obtained from Mahalat Mousa Station belonging to Animal Production Res. Institute, whole raw cow milk from Gemaza Station belongs to Animal Production Research Institute, ARC., Camel milk from Marsa Matroh Station belongs to Animal Production Research Institute, ARC, and the goat milk from Sakha station belongs to Animal Production Research ARC.

UF White soft cheese (3\% salt) and yoghurt (prepared from whole buffalo milk) were obtained from the Dairy Processing Unit belong to Animal Production Research Institute. Skim milk powder and processed cheese were randomly collected from the local market in Cairo and stored in refrigerator at $5 \pm 1$ until analysis.

All samples were firstly analyzed for its chemical composition (total solids, fat, protein, lactose and ash) and $\mathrm{pH}$ according to AOCA (2007) which are illustrated in Tables (1) and (2).

Table 1. Chemical composition of tested milk samples

\begin{tabular}{|c|c|c|c|c|}
\hline \multirow{2}{*}{ Parameters } & \multirow[b]{2}{*}{ Buffalo } & \multicolumn{2}{|c|}{ Milk Samnles } & \multirow[b]{2}{*}{ Goat } \\
\hline & & Cow & Camel & \\
\hline $\mathrm{pH}$ & & 6.60 & 6.5 & 6.6 \\
\hline T.S (\%) & & 11.45 & 11.70 & 12.20 \\
\hline Fat $(\%)$ & 6.10 & 3.00 & 3.60 & 3.80 \\
\hline$(\%)$ & & 3.1 & 3.0 & 3.50 \\
\hline & 4.7 & 4.60 & 4.40 & 4.10 \\
\hline Ash $(\%$ & 0.82 & 0.75 & 0.70 & 0.80 \\
\hline
\end{tabular}

Microwave digestion was used to prepare the spike samples. Ten $\mathrm{mL}$ of $\mathrm{HNO}_{3}$ was added to 
accurately weighed $\approx 0.5 \mathrm{~g}$ of the sample. A preloaded method for the MARS6 (CEM, Corporation, USA) microwave was used to digest the samples. Once cooled; the solution was diluted quantitatively to $25 \mathrm{~mL}$ using ultrapure distilled water.

Silicon standards from $0-1.50 \mathrm{mg} / \mathrm{l}$ were prepared from a stock standard solution of meta silicate pentahydrate $\left(\mathrm{Na}_{2} \mathrm{SO}_{3} .5 \mathrm{H}_{2} \mathrm{O}, \quad\right.$ Sigma Chemical Company). Stock solution (1000 mg Si/l) of meta silicate pentahydrate was prepared. The intensity was measured at $251.611 \mathrm{~nm}$. Standard reference materials do not exist for silicon in foods samples, so spiking and recovery experiments were used as before for quality assurance.

All measurements were performed using the innovative Agilent microwave plasma atomic emission spectrometry model 4200 MP-AES with nitrogen gas plasma supplied via an Agilent 4107 Nitrogen Generator. The generator alleviates the need and expense of sourcing analytical grade gases. The sample introduction system comprised a double-pass cyclonic spray chamber and the One Neb nebulizer. The innovative 4200 MP-AES features a second-generation waveguide and torch, with mass flow controlled nebulizer gas flow. The 4200 MP-AES has robust toroidal plasma with a central channel temperature of $\approx 5,000 \mathrm{~K}$ that eliminates many of the chemical interferences that are present in FAAS and expands the concentration working range of the $4200 \mathrm{MP}-\mathrm{AES}$ when compared with the FAAS. This means that the element specific sample preparation that is commonplace when using FAAS is not necessary when using the $4200 \mathrm{MP}$ AES, improving ease of use and reducing cost. Some modification has been performed with the first emerging model 4100 MP-AES into model 4200 MP-AES to enhance the performance and to resolve some drawbacks.

An Agilent SPS 3 auto sampler was used to deliver samples to the instrument, allowing the system to be operated unattended. The instrument operated in a fast sequential mode and featured a Peltier-cooled CCD detector. Background and spectral interferences could be simultaneously corrected easily and accurately using Agilent's MP Expert software. The concentrations of silicon were calculated according to the standard curve shown in Fig. (1)
Spiked sample was prepared by adding known concentrations of standard silicon to raw buffalo milk samples and soft cheese. The silicon in these samples was determined by using the same Agilent microwave plasma atomic emission spectrometry conditions. Recovery was calculated by the following equation:

$$
\mathbf{R} \%=\left(\mathbf{C}_{\mathrm{s}}-\mathbf{C}_{\mathrm{p}} / \mathbf{C}_{\mathrm{a}}\right) \cdot \mathbf{1 0 0}
$$

Where $\mathrm{R}(\%)$ is the percent recovery of added standard; $\mathrm{C}_{\mathrm{s}}$ is silicon concentration in the spiked sample; $\mathrm{C}_{\mathrm{p}}$ is the silicon concentration in the unspiked sample and $C_{a}$ is the concentration of silicon standard added. Also, the coefficient of variation was calculated as the following equation (Horwitz, 2003):

$$
\mathrm{C}_{\mathrm{v}}(\%)=(\mathrm{SD} / \text { mean }) .100
$$

\section{RESULTS AND DISCUSSION}

Silicon concentration in milk and in certain dairy products were determined by microwave plasma atomic emission spectrometry. The standard curve for silicon determination was represented in Fig.(1). The correlation between intensity and concentration showed a linear response with excellent correlation coefficient ( $\mathrm{r}$ $=1)$.

The validation of this method was evaluated by determination of recovery of silicon standard in spiked samples of buffalo milk and soft cheese as shown in table (3). It was found that the recoveries of silicon standard in buffalo milk samples were $98-100 \%$ for concentrations 1.00 and $2.00 \mathrm{ppm}$ respectively (Table $3)$. The data also showed the recoveries of the same concentrations of silicon standard in cheese samples were 96 and $98 \%$, respectively. These demonstrated the satisfactory recovery of the method on the tested dairy samples. The results of linearity and recovery indicated that the microwave plasma atomic emission spectrometry method is reliable for quantifying silicon in dairy samples.

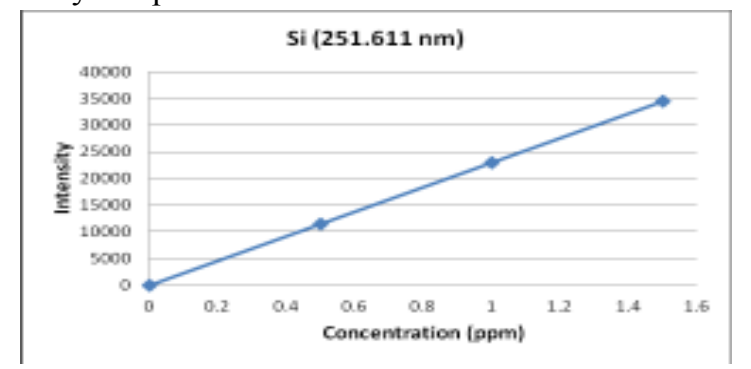

Fig. 1. Standard Curve of Silicon

Table 3. Recovery of silicon standard in buffalo milk and soft cheese

\begin{tabular}{lccccc}
\hline Samples & Si standard & ppm & Original Si in milk and soft cheese ppm & Si recovered ppm & Recovery $\%$ \\
\hline \multirow{2}{*}{ Milk } & 0.50 & 0.20 & 0.69 & 98 \\
\multirow{2}{*}{ Soft cheese } & 2.00 & 0.20 & 2.20 & 100 \\
& 0.50 & 4.4 & 4.88 & 96 \\
\hline
\end{tabular}

Silicon concentration in milk from different species

Table (4) showed the silicon concentration in milk from different species (buffalo, cow, camel and goat). It was found that the maximum concentration of silicon was in camel milk samples (mean $=3.34 \pm 0.12$ ppm) with correlation variation $3.59 \%$, and the minimum concentration was in buffalo milk samples (mean $=0.2 \pm 0.01 \mathrm{ppm}$ ) with coefficient of variation $5 \%$. While silicon concentration in cow and goat milk samples were $0.94 \pm 0.03$ and $2.28 \pm 0.09 \mathrm{ppm}$ with coefficient of variation 3.19 and $3.95 \%$ respectively.

Table 4. Silicon concentration in milk from different species

\begin{tabular}{lccc}
\hline Milk types & \multicolumn{2}{c}{ Silicon concentration (ppm) } \\
& Range & Mean \pm SD & CV \% \\
\hline Buffalo milk & $0.18-0.22$ & $0.20 \pm 0.01$ & 5.00 \\
Cow milk & $0.90-0.98$ & $0.94 \pm 0.03$ & 3.19 \\
Camel milk & $3.24-3.44$ & $3.34 \pm 0.12$ & 3.59 \\
Goat milk & $2.20-2.35$ & $2.28 \pm 0.09$ & 3.95 \\
\hline
\end{tabular}


Regarding the silicon concentration in certain dairy products (fresh skim milk, skim milk powder, white soft cheese, processed cheese and yoghurt) were represented in Table (5). The mean values of fresh skim milk and skim milk powder were $0.80 \pm 0.04$ and 33.11 $\pm 2.30 \mathrm{ppm}$, respectively. The average of silicon in fresh skim milk agreed with Powell et al., (2005), but the marked skim milk powder was higher than that reported by Bowen, \& Peggs, (1984), who found that silicon concentration in skim milk were in range 20 to 27 $\mathrm{mg} / \mathrm{kg}$ dry wt. Higher level of silicon was detected in processed cheese (5.80 ppm \pm 0.30$)$, compared with white soft cheese $(4.36 \pm 0.23)$. These findings are in harmony with those reported by Powell et al., (2005). Moreover, the results appeared that yoghurt contained higher silicon concentration than fresh milk and cheeses. Data also showed that the coefficient variation of all samples ranged from 3.11 to $6.95 \mathrm{ppm}$ (Table 5).

Table 5. Silicon concentration in skim milk and some dairy products

\begin{tabular}{|c|c|c|c|}
\hline \multirow{2}{*}{ Items } & \multicolumn{3}{|c|}{ Silicon concentration (ppm) } \\
\hline & Range & Mean \pm SD & CV\% \\
\hline Fresh skim milk & $0.74-0.85$ & $0.80 \pm 0.04$ & 5.00 \\
\hline Skim milk powder & $30.75-35.50$ & $33.11 \pm 2.30$ & 6.95 \\
\hline Soft cheese & $4.27-4.50$ & $4.36 \pm 0.23$ & 5.28 \\
\hline Processed cheese & $5.53-6.12$ & $5.80 \pm 0.30$ & 5.17 \\
\hline Yoghurt & $13.10-13.85$ & $13.50 \pm 0.42$ & 3.11 \\
\hline
\end{tabular}

\section{CONCLUSION}

The present study demonstrated suitability of the microwave plasma atomic emission spectrometry method for determination of silicon in milk and dairy products. Generally, milk and its products are considered of low silicon concentration. The highest value of silicon found in camel milk, followed by gradual decrease in goat, cow, and buffalo milks, respectively. Processed cheese contained higher level of silicon than soft cheese. The fermented milk as yogurt was the highest in silicon concentration. compared to milk and cheeses. These results give data for the silicon concentration of some Egyptian milks and dairy products, which are important for estimation of dietary intakes of silicon in the Egyptian population and declare the role of dietary silicon in African human health.

\section{REFERENCES}

AOAC (2007). Association of Official Analytical Chemists. Official Methods of Analysis 18th Ed., Washington, D.C ,USA.

.Bowen, H.J.M and Peggs, A. (1984). Determination of the silicon concentration of food. J. Sci. Food Agric 35, 1225-1229.

Expert Group on Vitamins and Minerals (2003). Safe Upper Levels for Vitamins and Minerals. London: Food Standards Agency.

Jugdaohsingh R, Tucker KL, Qiao N, Cupples LA, Kiel DP and Powell JJ (2004). Dietary silicon intake is positively associated with bone mineral density in men and pre- menopausal women of the Framingham Offspring Cohort. J. Bone Miner Res 13, 297-307.

Juhdaohsingh, R. (2007). Silicon and bone health. J. Nutr. Health Aging 11 (2), $99-110$.

Horwitz , W. (2003) . Validation: An invisible component of measurement. Arlington, VA: AOAC International. Cited from: Gao, Y., Guo, F., Gokavi, S., Chow, A., Sheng, Q., Guo, M., (2008). Quantification of water-soluble vitamins in milkbased infant formulae using biosensor-based assays. Food Chemistry 110, 769-776.

Powell, J.J.; McNaughton, S.A; Juhdaohsingh, R.; Anderson,S.H.C; Dear, J.; Khor, F. ; Mowatt, L; Gleason, K.L.; Sykes, M. ; Thompson, R.P.H; Bolton-Smith, C. and Hodson, M.G. (2005).A Provisional database for the silicon concentration of foods in the United Kingdom. .British J. of nutrition, 94, $804-812$.

Reffitt, D.M; Jugdaohsingh, R;Thompson, R.P.H. and Powell, J.J. (1999). Silicic acid: its gastrointestinal uptake and urinary excretion in man and effects on aluminium excretion. J. Inorg. Biochem. 76, 141147.

Sripanyakorn ,S. ; Jugdaohsingh, R. ; Thompson, R. P. H. and Powell, J. J. (2005). Dietary silicon and bone health. British Nutrition Foundation Nutrition Bulletin 30,222-230

Zhaoping, Li; Karp, H. Zerlin, A; Lee, T. Y. A.; Carpenter, C. and Heber, D. (2010). Absorption of Silicon from artesian aquifer water and its impact on bone health in postmenopausal women: a 12 week pilot study. Nutrition Journal, 9: 44.

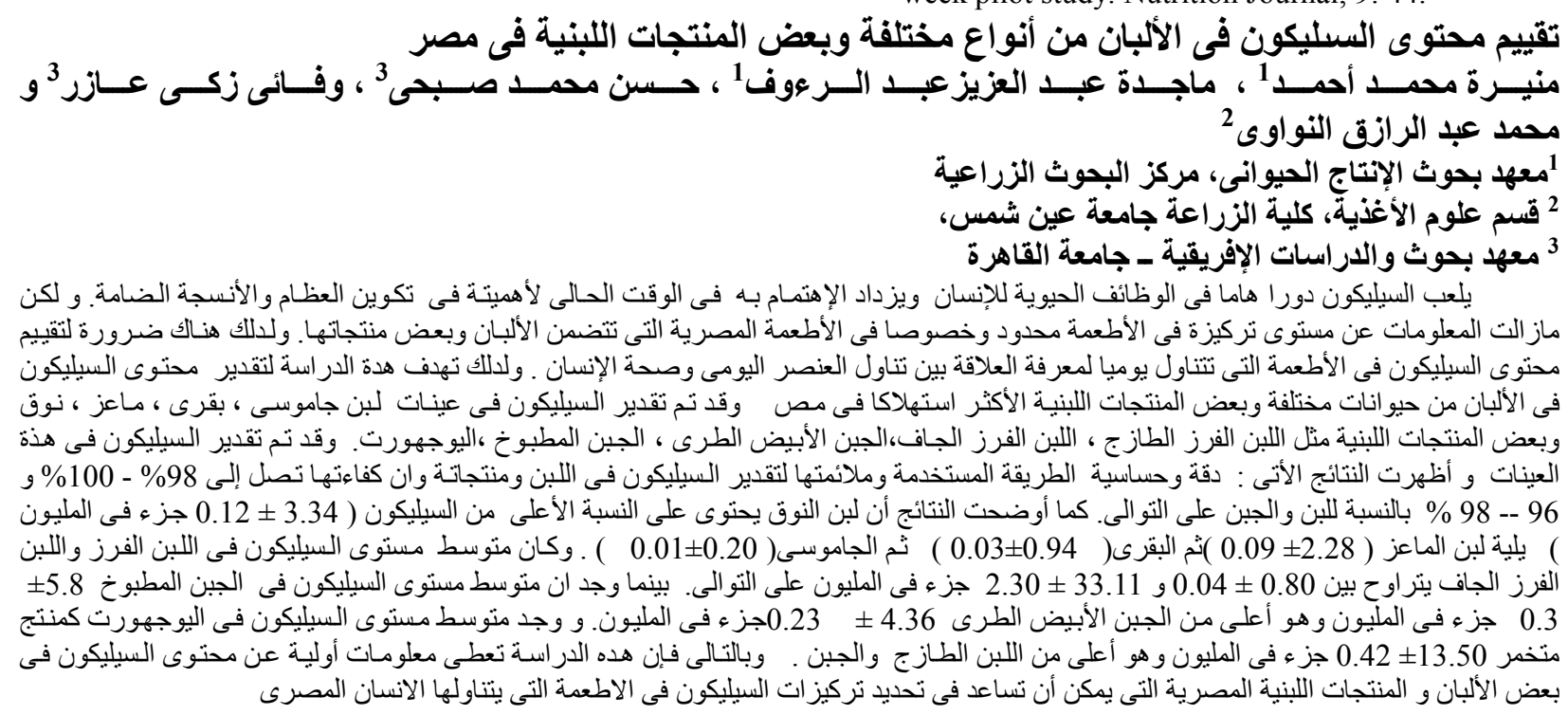


Mounira M. Ahmed et al. 